\begin{tabular}{|c|c|c|}
\hline $\begin{array}{l}\text { PKS } \\
\text { PUBLIC } \\
\text { KNOWLEDGE } \\
\text { PROSECT }\end{array}$ & $\begin{array}{c}\text { REVISTA DE GEOGRAFIA } \\
\text { (RECIFE) } \\
\text { http://www.revista.ufpe.br/revistageografia }\end{array}$ & 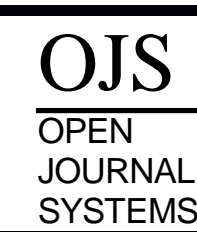 \\
\hline
\end{tabular}

\title{
O ACESSO Às POLÍTICAS PÚBLICAS DE DESENVOLVIMENTO RURAL PELA PRODUÇÃO CAMPONESA EM GOIÁS: RESULTADOS PARA AS MRG'S DE CATALÃO E SUDOESTE DE GOIÁS ${ }^{1}$
}

\author{
Ana Flávia Soares Carneiro ${ }^{1}$, Adriano Rodrigues de Oliveira ${ }^{2}$ \\ ${ }^{1}$ Universidade Federal de Goiás (UFG). Integrante do Grupo de Estudos e Pesquisas Trabalho, Território e \\ Políticas Públicas (TRAPPU) vinculado ao Laboratório de Estudos e Pesquisas das Dinâmicas Territoriais \\ (LABOTER).E-mail: anafscarneiro@gmail.com \\ ${ }^{2}$ Docente dos Cursos de Graduação e Pós-Graduação em Geografia do Instituto de Estudos Socioambientais \\ (IESA) da Universidade Federal de Goiás (UFG). Líder do Grupo de Estudos e Pesquisas Trabalho, Território e \\ Políticas Públicas (TRAPPU) vinculado ao Laboratório de Estudos e Pesquisas das Dinâmicas Territoriais \\ (LABOTER).E-mail: adriano.ufg@gmail.com
}

Artigo recebido em 15/04/2018 e aceito em 30/08/2018

\begin{abstract}
RESUMO
As políticas públicas por meio de programas de mercados institucionais têm respaldado a produção e comercialização dos produtos oriundos de famílias camponesas. No estado de Goiás, estes programas foram implementados a partir de 2003, a fim de promover o acesso ao mercado dos produtos oriundos dos agricultores familiares, assentados rurais, comunidades tradicionais e outros grupos. O texto apresenta aspectos geográficos e estatísticos que englobam os dados referentes ao desenvolvimento de três programas de mercados institucionais (Programa de Aquisição de Alimentos, Programa Nacional de Alimentação Escolar e Programa Nacional de Produção e Uso de Biodiesel) em Goiás, com enfoque nas Microrregiões do Sudoeste de Goiás e a Microrregião de Catalão por meio de mapas, tabelas e gráficos ilustrativos.
\end{abstract}

Palavras-chave: Políticas públicas; Mercados institucionais; Desenvolvimento rural.

\section{THE ACCESS TO PUBLIC POLICIES OF RURAL DEVELOPMENT BY THE PEASANT PRODUCTION IN THE STATE OF GOIÁS (BRAZIL): RESULTS FOR THE MICRO REGIONS OF CATALÃO AND SOUTHWEST OF GOIÁS}

\begin{abstract}
Public policies through institutional markets have been backed up the production and commercialization of goods produced by peasant families. In the state of Goiás, these programs were implemented from 2003 to promote the access to the market of products native of family farmers, rural seated people, traditional communities and other groups. The text presents statistics aspects that encompass data referred to the development of three programs of institutional markets (Food Acquisition Program, Nation Program of School Feeding and National Program of Production and Use of Biodiesel) in Goiás, focusing in the Micro regions of the Southwest of Goiás and of Catalão through maps, tables and illustrative graphics.
\end{abstract}

Keywords: Public policies; Institutional markets; Rural development.

\footnotetext{
${ }^{1}$ Pesquisa inserida nos projetos de pesquisa intitulados "O associativismo e desenvolvimento rural em Goiás: uma análise das estratégias de organização do agronegócio e da agricultura familiar” CHAMADA PÚBLICA $\mathrm{N}^{\circ}$ 05/12 FAPEG/UNIVERSAL e "Políticas Públicas de Desenvolvimento Rural em Goiás: uma análise do PAA e do PNPB" com financiamento da Chamada Universal MCTI/CNPq 14/2014.
} 


\section{INTRODUÇÃO}

Uma política pública se define como "uma diretriz elaborada para enfrentar um problema público" (SECCHI, 2013, p. 2). O autor acrescenta que as políticas públicas possuem dois elementos fundamentais, sendo eles: a intencionalidade pública e a resposta a um problema público, ou seja, “a razão para o estabelecimento de uma política pública é o tratamento ou resolução de um problema entendido como coletivamente relevante" (p.2)

As políticas públicas são principalmente de cunho governamental, sendo elaboradas exclusivamente pelo Estado, embora atores não estatais possam influenciar em seus processos de confecção e implementação, não intervindo nos processos de decisão e liderança dos projetos (SECCHI, 2013).

O presente texto apresenta uma análise sobre as políticas públicas de desenvolvimento rural no estado de Goiás, sobretudo nas microrregiões de Catalão e Sudoeste de Goiás. O olhar da pesquisa se volta para os seguintes programas: Programa de Aquisição de Alimentos (PAA), Programa Nacional de Alimentação Escolar (PNAE) e Programa Nacional de Produção e Uso de Biodiesel (PNPB).

O objetivo principal dessa pesquisa é analisar os entraves da produção camponesa aos programas de acesso aos mercados institucionais, com destaque ao PAA, PNAE e PNPB em Goiás, buscando compreender os efeitos desses programas para a formação de organizações coletivas como associações e cooperativas agrícolas, e a partir da sistematização dos dados, averiguar a importância dessas políticas públicas de desenvolvimento rural para a reprodução social e econômica da agricultura camponesa.

Foram utilizados como instrumentos metodológicos para a construção do texto: i) revisão bibliográfica; ii) atuação junto ao Grupo de Estudos e Pesquisas Trabalho, Território e Políticas Públicas (TRAPPU), vinculado ao Laboratório de Estudos e Pesquisas das Dinâmicas Territoriais (LABOTER) do IESA/UFG; iii) reuniões coletivas de condução de pesquisas sobre o tema; iv) levantamento de dados em fontes secundárias; e v) sistematização das informações obtidas por meio de tabelas, gráficos e, sobretudo, mapas.

Os mapas confeccionados para a síntese dos dados adquiridos foram elaborados no software ArcGIS 10.1, no qual todas as bases cartográficas foram projetados no Sistema de Referência Geocêntrico para as Américas 2000, SIRGAS 2000, pois é esse datum que possui uma maior precisão geográfica para o continente.

As visitas técnicas às áreas de estudo foram desenvolvidas, além dos autores, por outros integrantes da equipe de pesquisa que desenvolve o projeto da Chamada Universal do 
CNpq 14/2014, que esteve em campo em diversas ocasiões para a obtenção de informações e dados quali-quantitativos.

\section{O PROGRAMA DE AQUISIÇÃO DE ALIMENTOS (PAA)}

Criado no ano de 2003, o Programa de Aquisição de Alimentos - PAA é amparado pelo art. 19 da Lei ${ }^{\circ} 10.696$, de 02 de julho do mesmo ano e possui como finalidades básicas: promover o acesso à alimentação e incentivar a agricultura familiar (BRASIL, 2015). Deste modo, para:

[...] o alcance desses dois objetivos, o programa compra alimentos produzidos pela agricultura familiar, com dispensa de licitação, e os destina às pessoas em situação de insegurança alimentar e nutricional e àquelas atendidas pela rede socioassistencial, pelos equipamentos públicos de segurança alimentar e nutricional e pela rede pública e filantrópica de ensino" - (BRASIL, 2015).

De acordo com Peixoto (2016), a Pesquisa Nacional por Amostra de Domicílios (PNAD), divulgada em 2004 pelo Instituto Brasileiro de Geografia e Estatística - IBGE revelou que 34,9\% dos domicílios (um total de 18.035.000) apresentavam situações leves, moderadas ou graves de insegurança alimentar. Peixoto (2016, p. 54) afirma que "o PAA é a alternativa formulada para atenuar esse problema, representando uma ação estratégica do Programa Fome Zero, por meio da valorização da produção da agricultura familiar, para atender a demanda de distribuição de alimentos no país".

O programa que visa o enfrentamento da fome e da pobreza no Brasil pode ser acessado, segundo a Secretaria Especial de Agricultura Familiar e do Desenvolvimento Agrário, por "agricultores familiares, assentados da reforma agrária, comunidades indígenas e demais povos e comunidades tradicionais ou empreendimentos familiares rurais portadores de DAP - Declaração de Aptidão ao Pronaf ${ }^{2 \%}$. (BRASIL, não datado).

A secretaria afirma ainda que o programa é executado com seus recursos, juntamente ao "Ministério do Desenvolvimento Social e Agrário (MDSA), em parceria com estados, municípios e com a Companhia Nacional de Abastecimento (CONAB)". (BRASIL, não datado).

No intuito de compreender o alcance do Programa de Aquisição de Alimentos no plano estadual, próximo item, faremos um aprofundamento dos dados por meio da

\footnotetext{
${ }^{2}$ PRONAF - O Programa Nacional de Fortalecimento da Agricultura Familiar: financia projetos individuais ou coletivos, que gerem renda aos agricultores familiares e assentados da reforma agrária. Possui baixas taxas de juros de financiamentos rurais. (BRASIL, Sead, não datado).
} 
espacialização de algumas dimensões do Programa no estado de Goiás e nas microrregiões de Catalão e do Sudoeste de Goiás.

\section{O PROGRAMA DE AQUISIÇÃO DE ALIMENTOS EM GOIÁS}

As informações utilizadas para a elaboração das sínteses aplicadas nesta seção foram obtidas pela Companhia Nacional do Abastecimento (CONAB), oriundas da divisão específica do Programa de Aquisição de Alimentos.

A CONAB é vinculada ao Ministério de Agricultura, Pecuária e Abastecimento (MAPA) e fora criada em 12 de abril de 1990, por meio da Lei $n^{\circ}$ 8.029. É de responsabilidade do órgão "gerir as políticas agrícolas e de abastecimento, visando assegurar o atendimento das necessidades básicas da sociedade, preservando e estimulando os mecanismos de mercado" (CONAB, sem data).

A companhia responde por diversos programas voltados para o abastecimento do país. A CONAB executa, junto a outros órgãos governamentais, o PAA, com o objetivo de garantir a comercialização da agricultura camponesa, bem como oferecer estes alimentos à população em situação de vulnerabilidade social, ou seja, o programa se insere nos pressupostos da Segurança Alimentar e Nutricional. (CONAB, sem data).

A espacialização a seguir realizada levando em consideração a quantidade de agricultores cadastrados, a quantidade (em $\mathrm{kg}$ ) de alimentos produzidos e o valor total da proposta, dos municípios cadastrados no Programa nos anos de 2010 e 2016, conforme os dados da CONAB. Foram envolvidas respectivamente 25 e 23 associações/cooperativas, respectivamente em 2010 e 2016, conforme os dados da CONAB. 


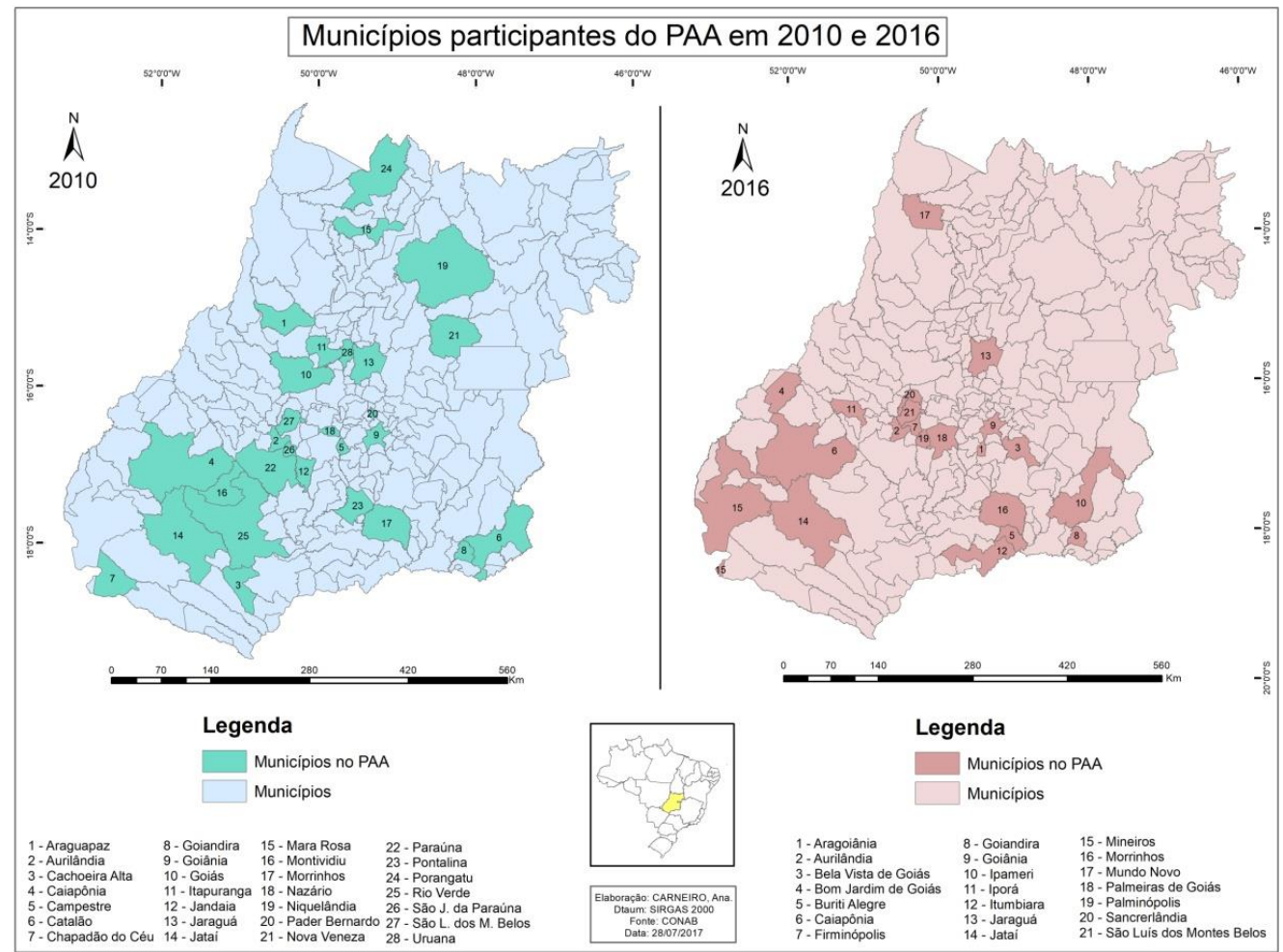

Figura 1: Espacialização dos municípios contemplados pelo PAA em 2010 e 2016

Na figura 1, é possível analisar a espacialização do PAA no estado de Goiás em dois recortes temporais: 2010 e 2016. Em 2010, 28 municípios localizados em diferentes regiões do estado foram contemplados. Em 2016, o número de municípios contemplados passa de 28 para 21. Neste ano podemos constatar a maior concentração na parte sul do estado, enquanto na região norte apenas dois municípios podem ser visualizados: Jaraguá e Mundo Novo.

Com base na correlação entre a quantidade de localidades contempladas pelo PAA nestes recortes temporais, podemos perceber que em momento algum são contemplados municípios da região nordeste do estado. Calaça e Dias (2010) e Correia (2010) apud Santos (2016) lembram que no estado, a expansão da fronteira agrícola redundou na desigualdade regional, configurando em contradições de usos dos solos e posses de terra.

A região nordeste do estado pouco foi influenciada pelo 'desenvolvimento rural' que beneficiou outras regiões do estado, a exemplo da porção sul, que abriga os maiores polos agrícolas do estado com destaque para a tríade do complexo grãos-carnes: Jataí, Rio Verde e Mineiros.

A figura 2, a seguir, quantifica os agricultores familiares por município no PAA. No ano de 2010 foram 1.092 cadastros no estado. Percebe-se que a discrepância em números de alguns municípios para outros tende a ser recorrente. Em locais onde há associações e cooperativas, a quantidade de produtores envolvidos torna-se maior. Costa et al (2015)

Carneiro e Oliveira, $2018 \quad$ ISSN 0104-5490 158


associa essa ocorrência ao fato das associações terem mais espaço no mercado do que os agricultores independentes.

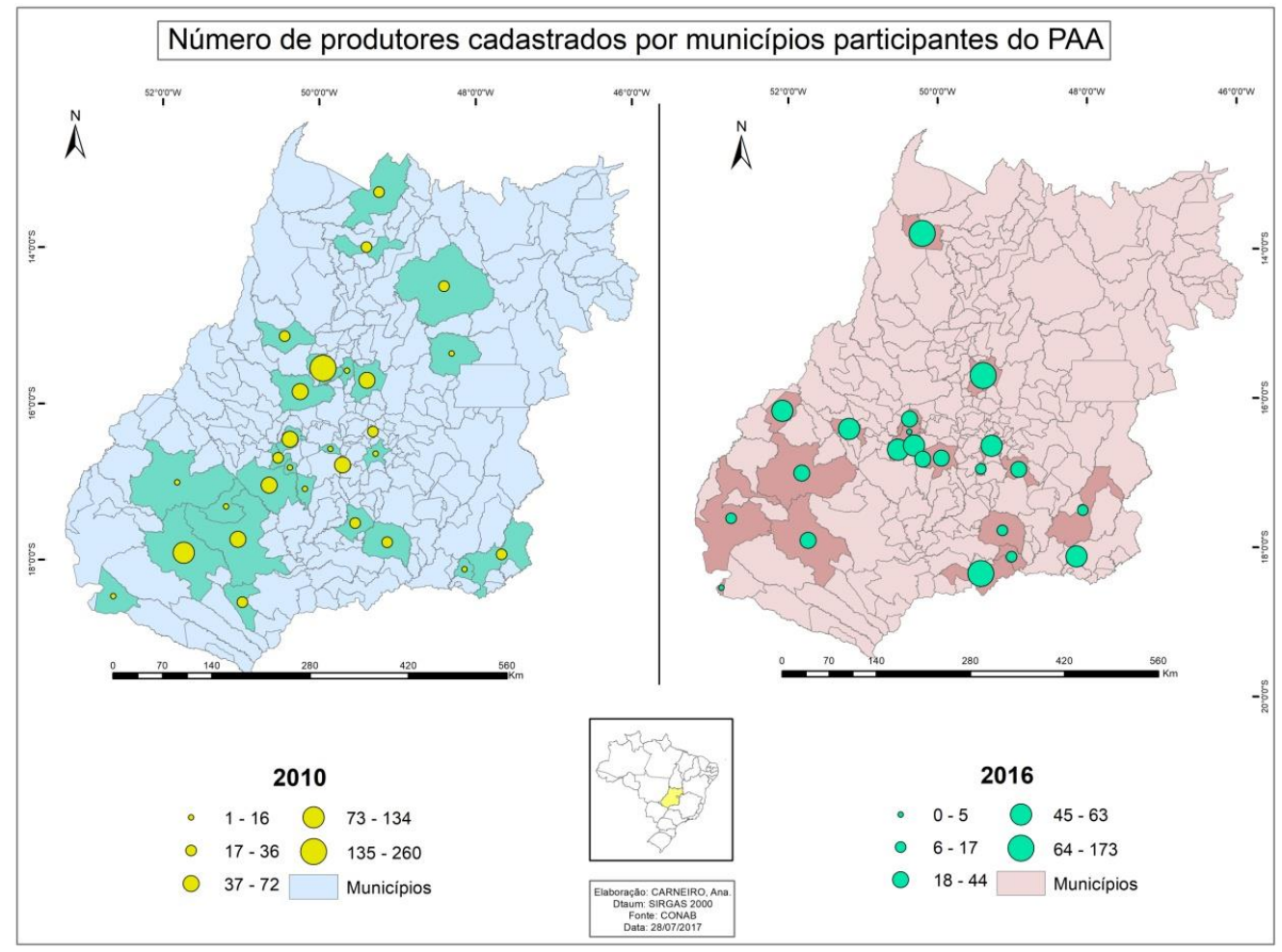

Figura 2: Número de agricultores cadastrados por municípios participantes no PAA em 2010 e 2016

Outro fator que contribui para as variadas quantidades de agricultores cadastrados são as modalidades do PAA. No ano de 2010, três modalidades do programa eram praticadas no estado: o CEDAF, o CPR - Doação e o CPR - Estoque. De acordo com a CONAB, estas modalidades possuem diferentes funcionalidades, sendo o CEDAF (Compra Direta da Agricultura Familiar) caracterizado pela aquisição direta de produtos como mandioca, feijão, milho, castanha, dentre vários, com os agricultores ou com as associações de agricultores. $\mathrm{Na}$ modalidade CPR Doação (Compra da Agricultura Familiar com Doação Simultânea), a cooperativa ou associação repassam seus produtos e os entregam diretamente em restaurantes populares, bancos de alimentos, asilos, APAES, abrigos e outros. Por fim, o CPR - Estoque (Formação de Estoque pela Agricultura Familiar) possibilita às organizações familiares obterem recursos para a aquisição de produtos da safra vigente, objetivando a formação de estoques, de produtos in natura e/ou processado/beneficiado/industrializado, criando condições para melhor comercializá-los quando propício. (CONAB, sem data). 


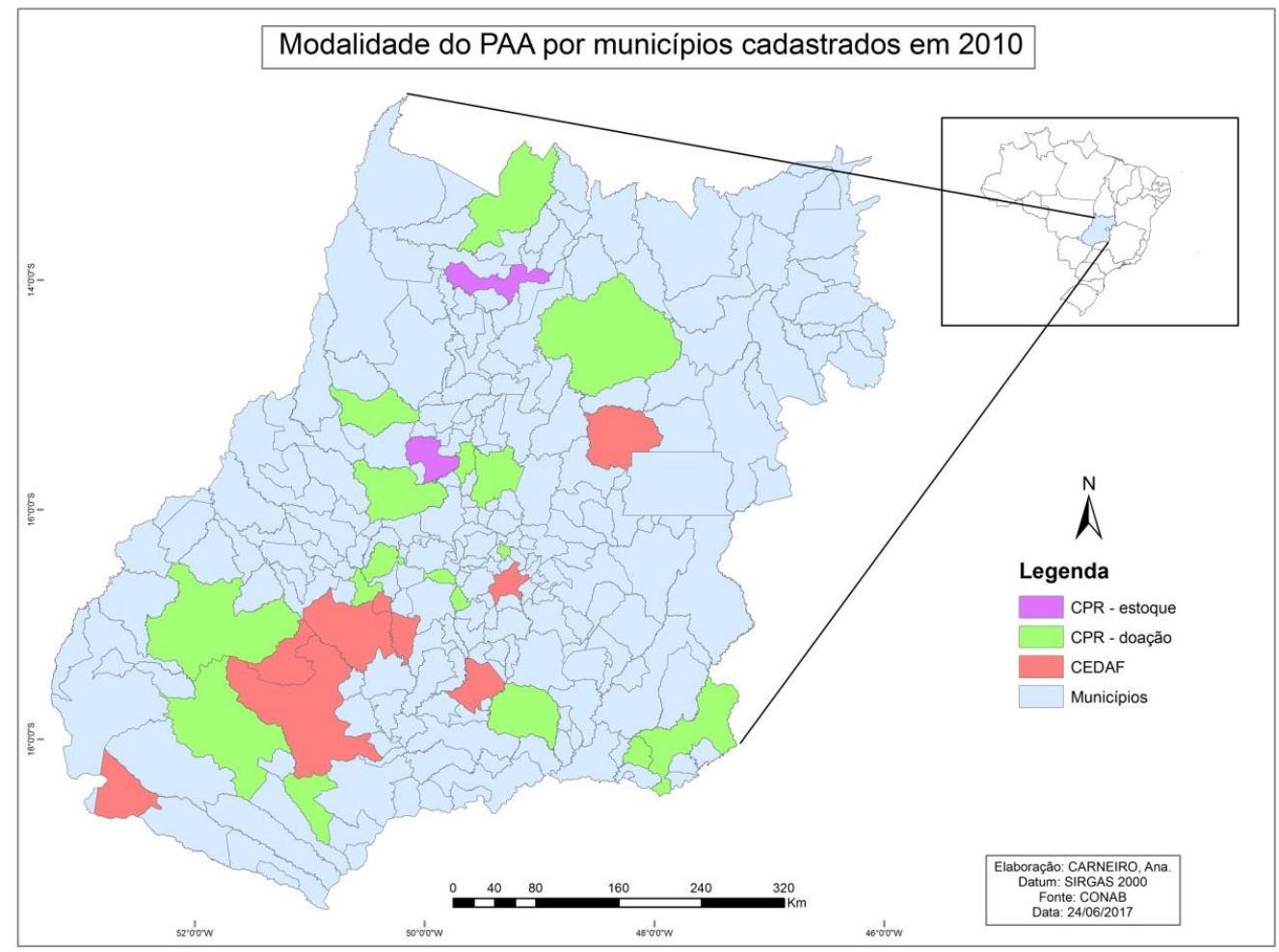

Figura 3: Modalidades do PAA praticadas nos municípios cadastrados em 2010

Nota-se portanto, que a única modalidade que negocia diretamente com o produtor idenpendente é o CEDAF, que como se pode ver na espacialização, ocorre em grandes proporções no estado. Como alguns municípios aparecem em mais de uma modalidade, para a elaboração do mapa da Figura 3, levou-se em consideração aquela modalidade que apresentava maior número de agricultores cadastrados.

Comparando ao primeiro ano averiguado, no ano de 2016 os números mostram-se menos heterogêneos, apesar de o total de cadastros não se discreparem tanto (1.092 em 2010 e 1.056 em 2016); a quantidade de municípios com participação de 0 - 5 produtores é menor; por outro lado, menos municípios apresentaram grandes números de participantes - apenas três ultrapassaram os 100 cadastrados: Novo Mundo (173), Jaraguá (117) e Itumbiara (100).

Quanto às modalidades praticadas, todos os municípios, com exceção de Goiânia, exercem a Compra Com Doação Simultânea - CDS, na qual os alimentos são adquiridos de associações/cooperativas "com vistas à doação para unidades recebedoras que atendam pessoas em situação de insegurança alimentar e nutricionais" (CONAB, 2014). A capital, além de desenvolver essa modalidade, abarca ainda a categoria Sementes, na qual as mesmas são adquiridas para a doação. As modalidades praticadas em 2016 inferem no fato de nesse ano, todos os agricultores cadastrados estarem inseridos em alguma associação. 


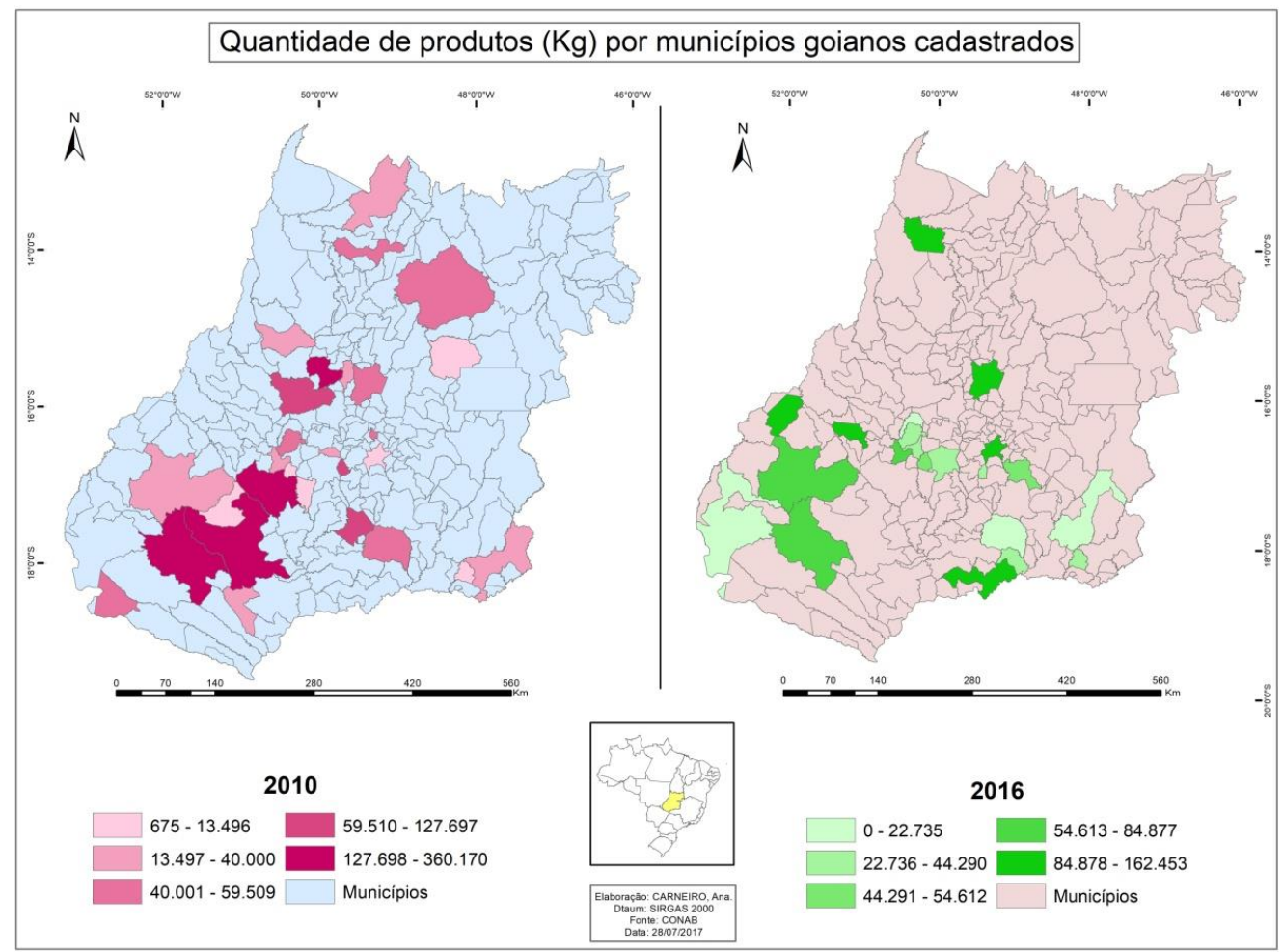

Figura 4: Distribuição de quantidade de produtos (em kg), conforme os municípios em 2010 e 2016

A figura 4 apresenta os municípios pela quantidade de produtos, em quilograma, gerados em 2010 e 2016. Nota-se que em 2010, os municípios que disponibilizaram as maiores quantidades de produtos se localizam na porção sul e centro do estado. No total foram 4.326,95 toneladas de alimentos disponibilizadas. Em 2016, este total se mostrou bem inferior ao que foi produzido em 2010, com apenas 1.525,95 toneladas.

A figura 5, última com dados relativos ao ano de 2010, revela o valor em real (R\$) obtido em cada município do PAA. Pode se notar, mais uma vez que os resultados que mais apresentaram destaque estão na porção sul do estado, mais especificamente nos municípios de Jataí, Rio Verde, Paraúna e Pontalina. Em todo o estado, foram aplicados R\$ 4.412.386,5 no programa.

Em contrapartida, o valor aplicado nos municípios quase duplicou, apresentando um total de R \$ 8.199.054,95, anunciando um montante de investimento bem superior ao aplicado em 2010. 


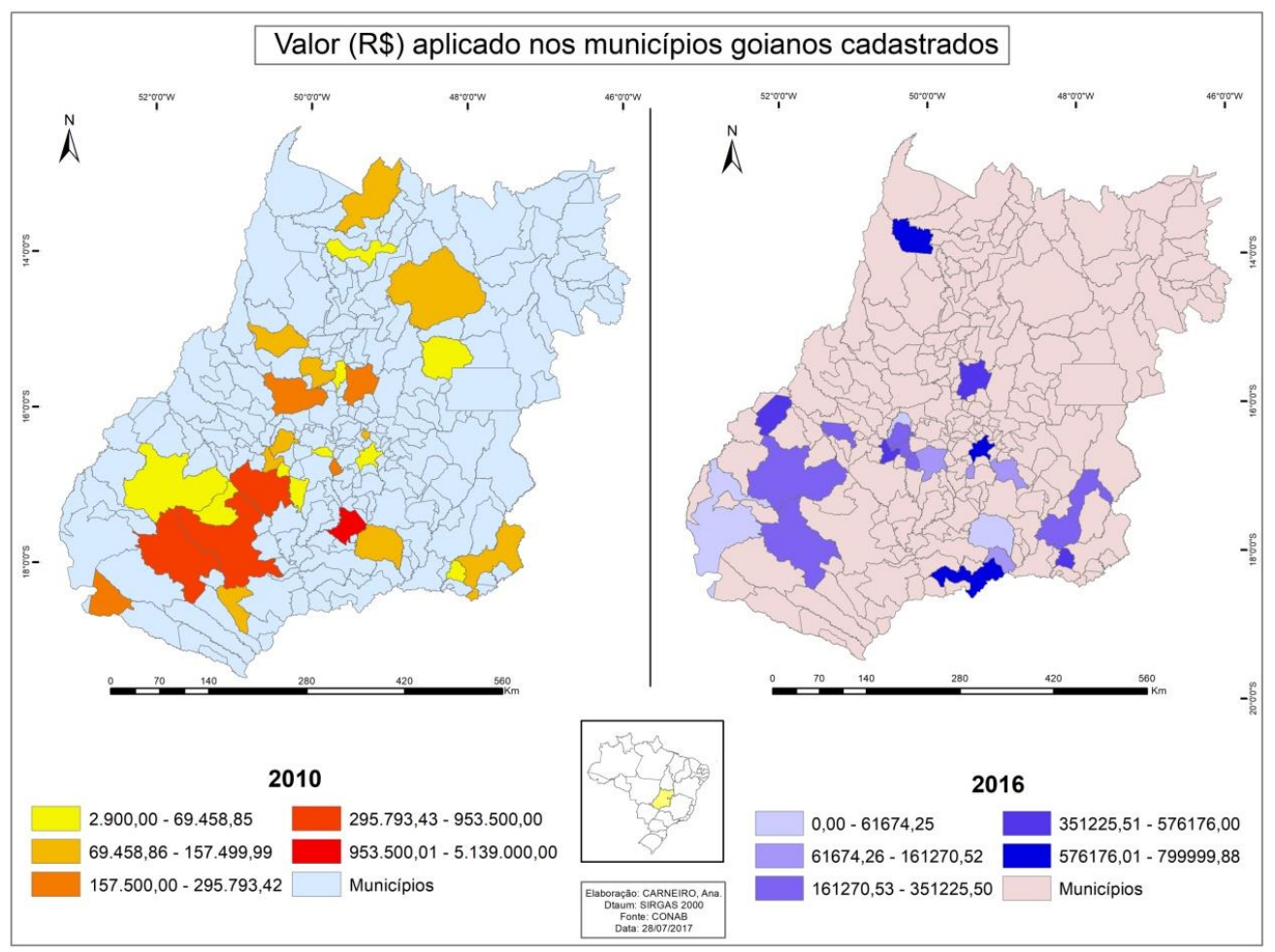

Figura 5: Montante investido em cada município participante do PAA em 2010 e 2016

A figura 5, com dados relativos PAA no estado, revela o valor em real (R\$) empregado em cada município participante. Em 2010, pode se notar que os resultados que mais apresentaram destaque estão na porção sul do estado, mais especificamente nas cidades de Jataí, Rio Verde, Paraúna e Pontalina. Neste ano, foram aplicados R 4.412.386,55 no programa. Em contrapartida, o valor aplicado nos municípios em 2016 quase duplicou, apresentando um total de $\mathrm{R} \$ 8.199 .054,95$, anunciando um montante de investimento bem superior ao aplicado em 2010.

\section{RESULTADOS DO PAA NAS MICRORREGIÕES DE CATALÃO E SUDOESTE DE GOIÁS}

De acordo com a Secretaria de Estado de Gestão e Abastecimento (SEGPLAN), o Instituto Brasileiro de Geografia e Estatística (IBGE) divide o Estado de Goiás em 18 Microrregiões Geográficas (Figura 6). 


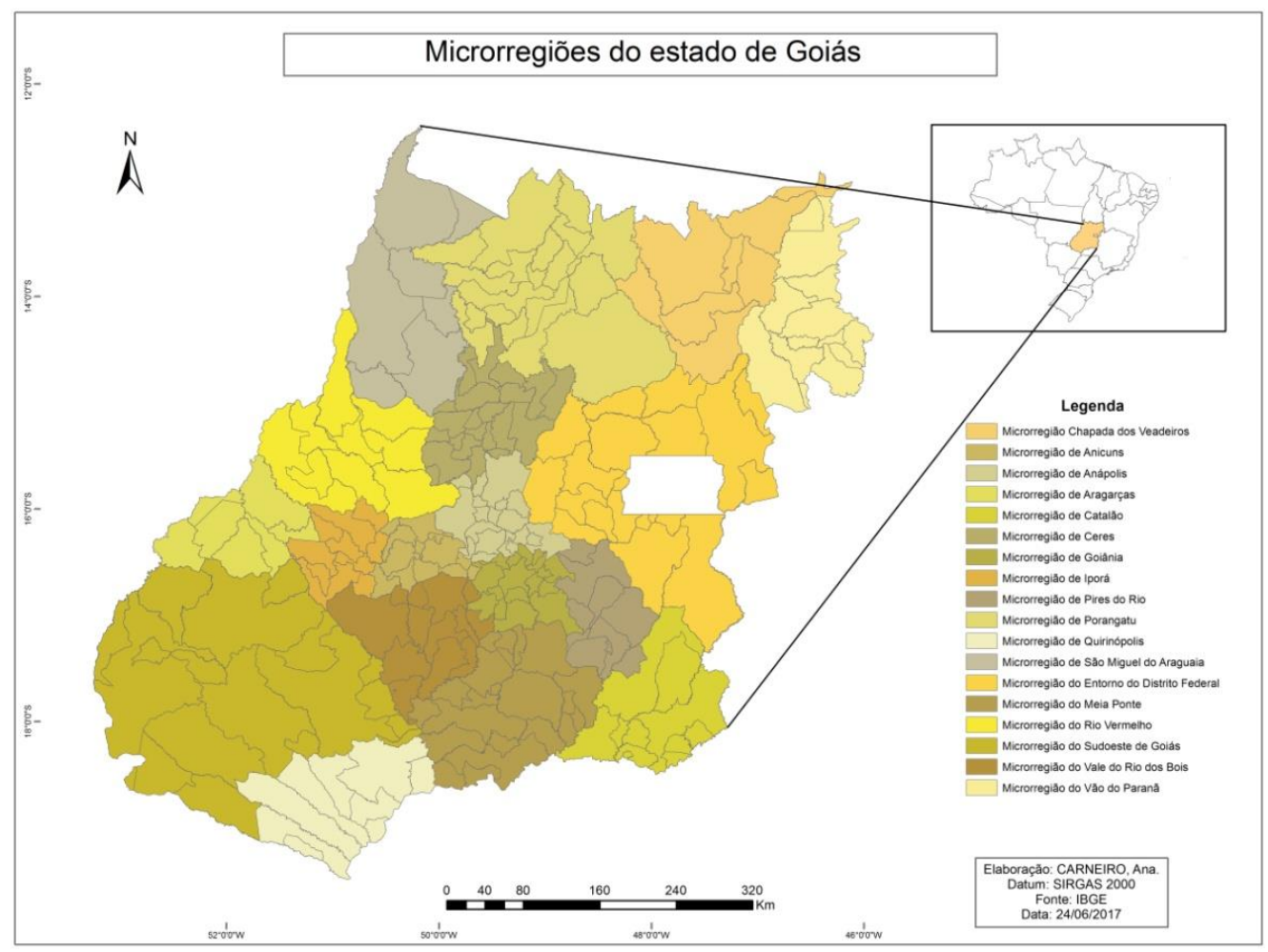

Figura 6: Microrregiões goianas ${ }^{3}$

Iremos especificar os dados para duas regiões localizadas ao sul do estado: a Microrregião do Sudoeste Goiano e a Microrregião de Catalão (figura 7). A MRG do Sudoeste Goiano engloba ao todo 18 municípios e localiza-se na fronteira de Goiás com os estados de Mato Grosso e Mato Grosso do Sul. O agronegócio fez da região uma das mais abastadas no que diz respeito à arrecadação econômica. Em 2013, a MRG obteve o segundo maior PIB do estado, segundo Oliveira (2017). A área possui uma extensão de 56.111,42 km², abrigando uma população estimada em 446.443, segundo dados do IBGE (2010).

\footnotetext{
${ }^{3}$ A secretaria caracteriza as microrregiões "como um conjunto de municípios, contíguos e contidos na mesma Unidade da Federação, definidos com base em características do quadro natural, da organização da produção e de sua integração" (2014, sem página). Ainda é definido que as microrregiões se integram às mesorregiões, que se organizam espacialmente em: estrutura da produção agropecuária, industrial, extrativismo mineral, características naturais, sociais ou econômicas semelhantes (Centro Goiano, Leste Goiano, Noroeste, Norte Goiano, Sul Goiano)
} 


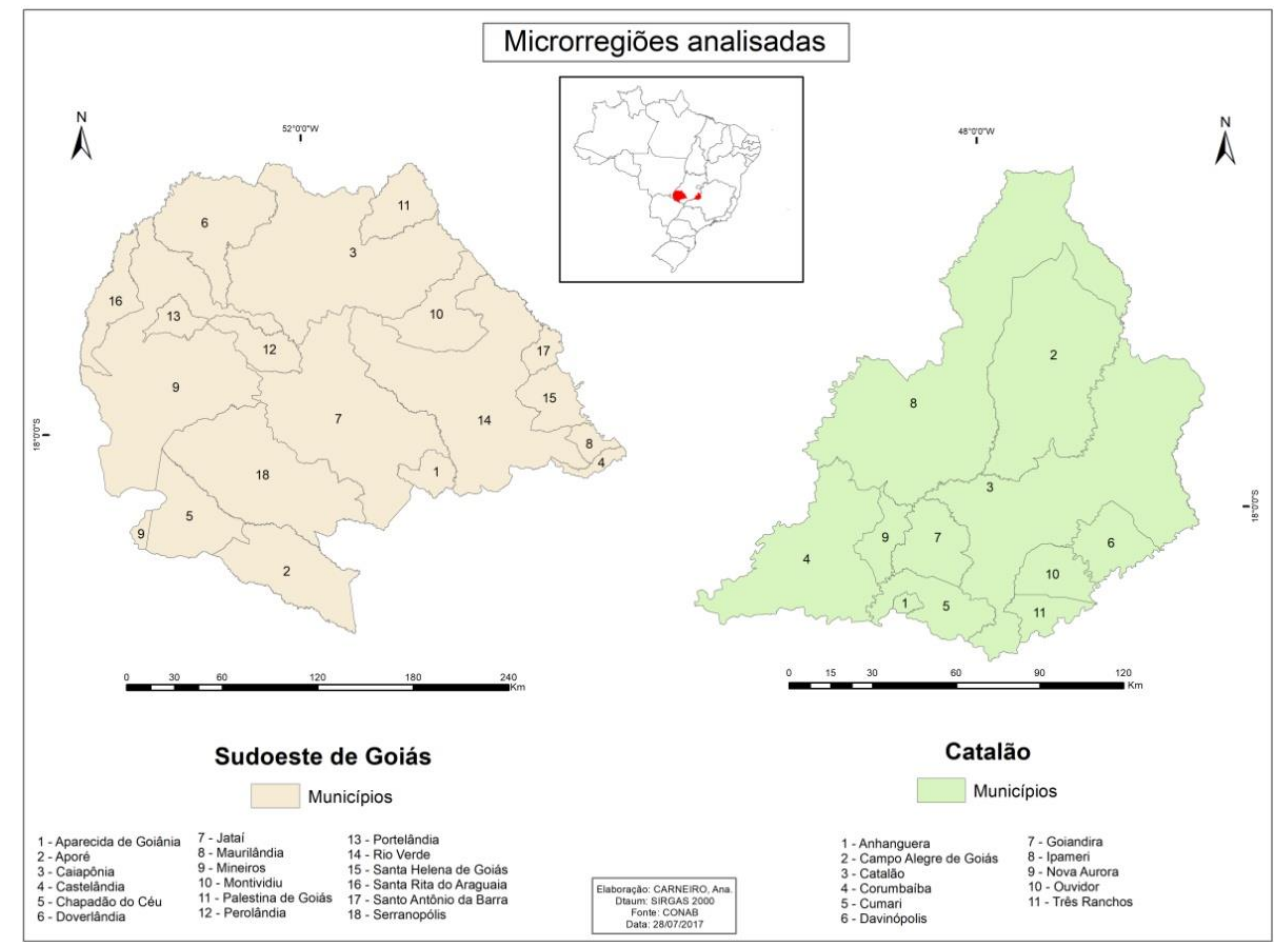

Figura 7: Municípios integrantes das Microrregião do Sudoeste de Goiás e Catalão

A Microrregião de Catalão faz fronteira com o estado de Minas Gerais e se divide em 11 municípios, como ser evidenciado na figura 7. É menor em comparação à MRG citada anteriormente no que diz respeito ao número de habitantes, área disposta e expresividade econômica (ambos possuem a mesma matriz financeira). A região distribui seus 165.101 habitantes em 15.206,84 km² de área (IBGE, 2010).

Para os mesmos itens analisados para o estado (número de agricultores, valor investido e quantidade de produtos gerados) no ano de 2010, podemos perceber que a participação dos municípios se mostrou baixa. A figura 8 ilustra para o ano citado, os aspectos em questão nas MRGs do Sudoeste de Goiás e Catalão, respectivamente.

Nota-se que na Microrregião Sudoeste, apenas 4 dos 18 municípios que a compõe estavam inseridos no programa: Montividiu, Chapadão do Céu, Caiapônia e Rio Verde. No que diz respeito ao número de produtores cadastrados, Rio Verde apresentou a maior quantidade (55), seguido por Caiapônia e Chapadão do Céu (13) e Montividiu (3). A MRG de Catalão, em 2010, apresentava 2 municípios participantes do Programa: Goiandira e Catalão. Para a quantidade de produtores cadastrados, Goiandira apresentou 3 e Catalão 31. 


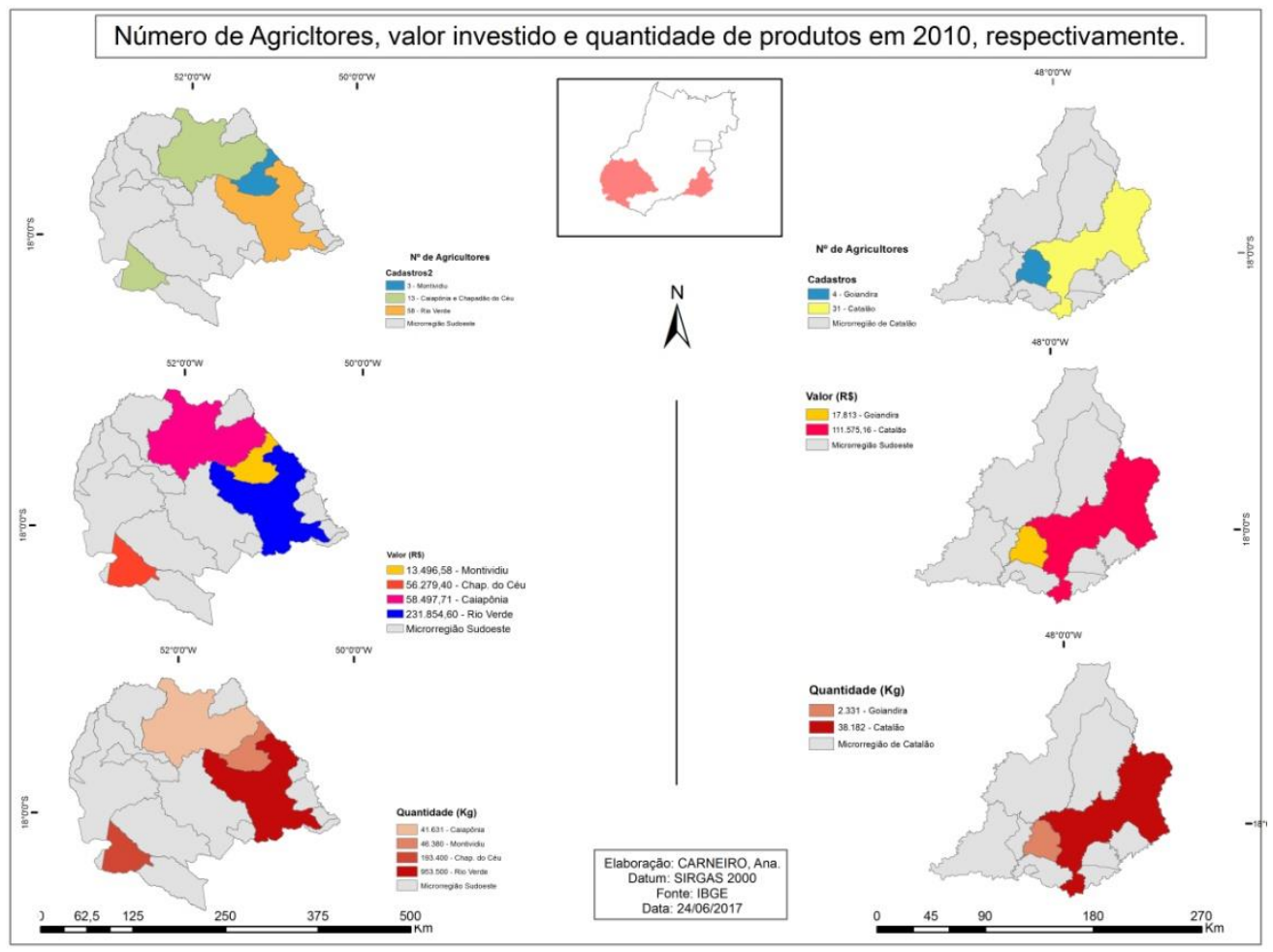

Figura 8: Programa de Aquisição de Alimentos nas microrregiões em análise em 2010

Na MRG Sudoeste, o município que mais recebeu recursos para o programa foi Rio Verde, com mais de R \$230.000,00. Caiapônia (cerca de R \$ 58.500,00), Chapadão do Céu (cerca de R\$ 56.300,00) e Montividiu (aprox. R\$13.500,00), aparecem em seguida. Na Microrregião de Catalão, Goiandira apresentou um montante inferior à Catalão (aproximadamente $\mathrm{R} \$ 18.000,00$ e $\mathrm{R} \$ 111.500,00$ respectivamente).

Quanto a quantidade de produtos gerados, em quilogramas, o ranking para a Microrregião do Sudoeste de Goiás expôs: Rio Verde em primeiro (953.500 kg), Chapadão do Céu em segundo (193.400 kg), Montividiu em terceiro (46.380 kg) e Caiapônia em quarto (41.631 kg). Na MRG de Catalão, a cidade homônima gerou 38.182 kg enquanto Goiandira gerou $2.331 \mathrm{~kg}$, em 2010 .

De acordo com a figura 9 referente a 2016, abaixo, percebe-se agora que apenas 3 municípios da Microrregião Sudoeste participam do programa: Mineiros, Caiapônia e Jataí. A MRG de Catalão continua com 2 municípios envolvidos, agora: Ipameri e Goiandira. Levando em consideração o número de agricultores do primeiro conjunto em análise, Mineiros cadastrou 14 produtores, Caiapônia 33 e Jataí 41. Enquanto que na Microrregião de Catalão Ipameri cadastrou 25 e Goiandira 60. 


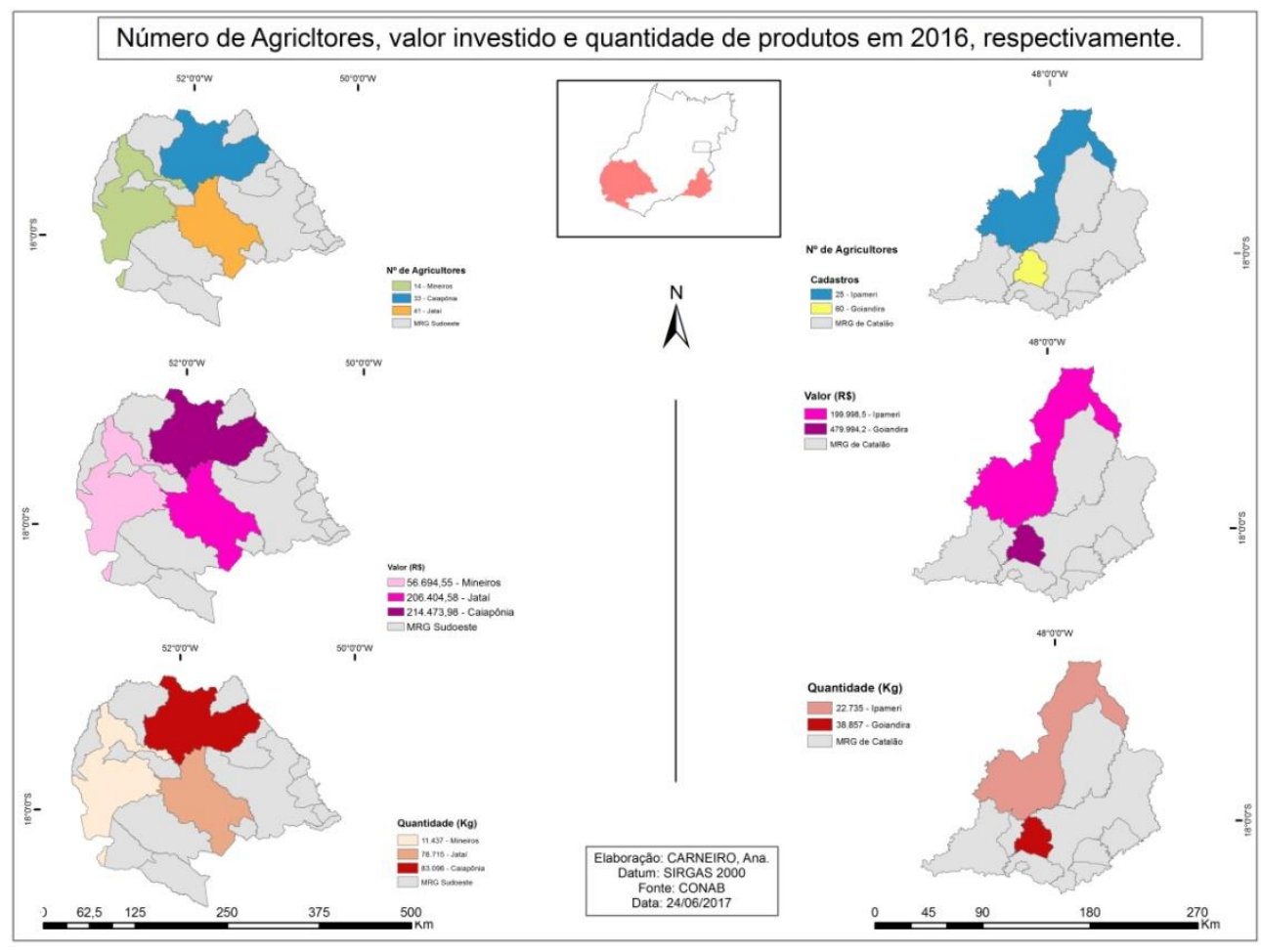

Figura 9: Programa de Aquisição de Alimentos nas Microrregiões em análise em 2016

Quanto aos valores de investimento, Caiapônia e Jataí apresentaram montantes superiores a duzentos mil reais, respectivamente $\mathrm{R} \$ 240.474,00$ e $\mathrm{R} \$ 206.405,00$. Mineiros foi a cidade de $M R G$ que menos recebeu ( $R$ \$ 56.694,55). Ipameri obteve $R \$ 199.998,50$, enquanto a cidade de Goiandira apresentou o maior valor entre todos os municípios: $\mathrm{R} \$$ $479.994,20$.

No que se refere ao quesito quantidade de produtos, a Microrregião do Sudoeste de Goiás teve como maior gerador o município de Caiapônia, com 83.096 kg; seguido por Jataí $(78.715 \mathrm{~kg})$ e Mineiros (11.437 kg). Na Microrregião de Catalão, a cidade que mais gerou produtos foi Goiandira, produzindo $38.857 \mathrm{~kg}$, enquanto Ipameri atingiu $22.735 \mathrm{~kg}$.

\section{O PROGRAMA NACIONAL DE ALIMENTAÇÃO ESCOLAR (PNAE)}

O Programa Nacional de Alimentação Escolar (PNAE) se constitui em um dos programas mais antigos que o governo brasileiro dispõe sobre a alimentação escolar no âmbito da Segurança Alimentar Nutricional (SAN), tendo sido criado em 1955 (BRASIL (2012). É considerado um dos mais abrangentes do mundo no que diz respeito ao atendimento escolar e alimentação saudável (BRASIL, 2014). A Cartilha Nacional da Alimentação Escolar, de 2014, indica como objetivos do PNAE: 
Contribuir para o crescimento e o desenvolvimento biopsicossocial a aprendizagem, o rendimento escolar e a formação de hábitos saudáveis dos alunos, por meio de ações de educação alimentar e nutricionais e da oferta de refeições que cubram as suas necessidades nutricionais durante o período em que permanecem na escola. (BRASIL, 2014).

O FNDE - Fundo Nacional de Desenvolvimento da Educação - afirma que o repasse de verbas do programa se dá de forma direta aos estados e municípios, baseando-se no Censo Escolar efetuado no ano anterior ao atendimento. Para o ano de 2012, o repasse era efetuado conforme a quantidade de estudantes dispostos em cada etapa escolar. O valor era então estipulado para cada dia letivo, por estudante, por modalidade de ensino (BRASIL, 2012):

- Creches: $\mathrm{R} \$ 1,07$

- Pré-escola: $\mathrm{R} \$ 0,53$

- Escolas indígenas e quilombolas: $\mathrm{R} \$ 0,64$

- Ensino fund. e médio: $\mathrm{R} \$ 0,36$

- Educação de jovens e adultos: R\$ 0,32

- Ensino integral: R\$1,07

- Programa de Fomento às Escolas de Ensino Médio em Tempo Integral: R \$ 2,00

- Alunos que frequentam o Atendimento Educacional Especializado no contraturno: R\$ 0,53

A partir de 2009, a Lei 11.947 que dispõe sobre a alimentação escolar, implementa em seu artigo de $\mathrm{n}^{\circ} 14$ a garantia de que:

Do total dos recursos financeiros repassados pelo FNDE, no âmbito do PNAE, no mínimo 30\% (trinta por cento) deverão ser utilizados na aquisição de gêneros alimentícios diretamente da agricultura familiar e do empreendedor familiar rural ou de suas organizações, priorizando-se os assentamentos da reforma agrária, as comunidades tradicionais indígenas e comunidades quilombolas (BRASIL, 2009, s/p).

Deste modo, essa regulamentação governamental se constitui num importante instrumento de garantia de recursos para o funcionamento deste programa como mercado institucional, assegurando por um lado a compra da produção camponesa, incentivando inclusive a formação de organizações coletivas como associações e cooperativas. Por outro lado, vai ao encontro da Segurança Alimentar e Nutricional, a partir do momento que possibilita o fornecimento de gêneros alimentícios oriundos da produção local e/ou regional. 
RESULTADOS DO PNAE NAS MICRORREGIÕES DE CATALÃO E SUDOESTE DE GOIÁS

Entre os anos de 2011 e 2015 houve um acréscimo na quantidade de recursos destinados às prefeituras do estado para a alimentação escolar. Em 2011, Goiás recebeu R\$ 86.996.346,00. Quatro anos depois, o valor enviado pelo programa aos municípios aumentou, atingindo o equivalente a $\mathrm{R} \$ 108.709 .317,60$.

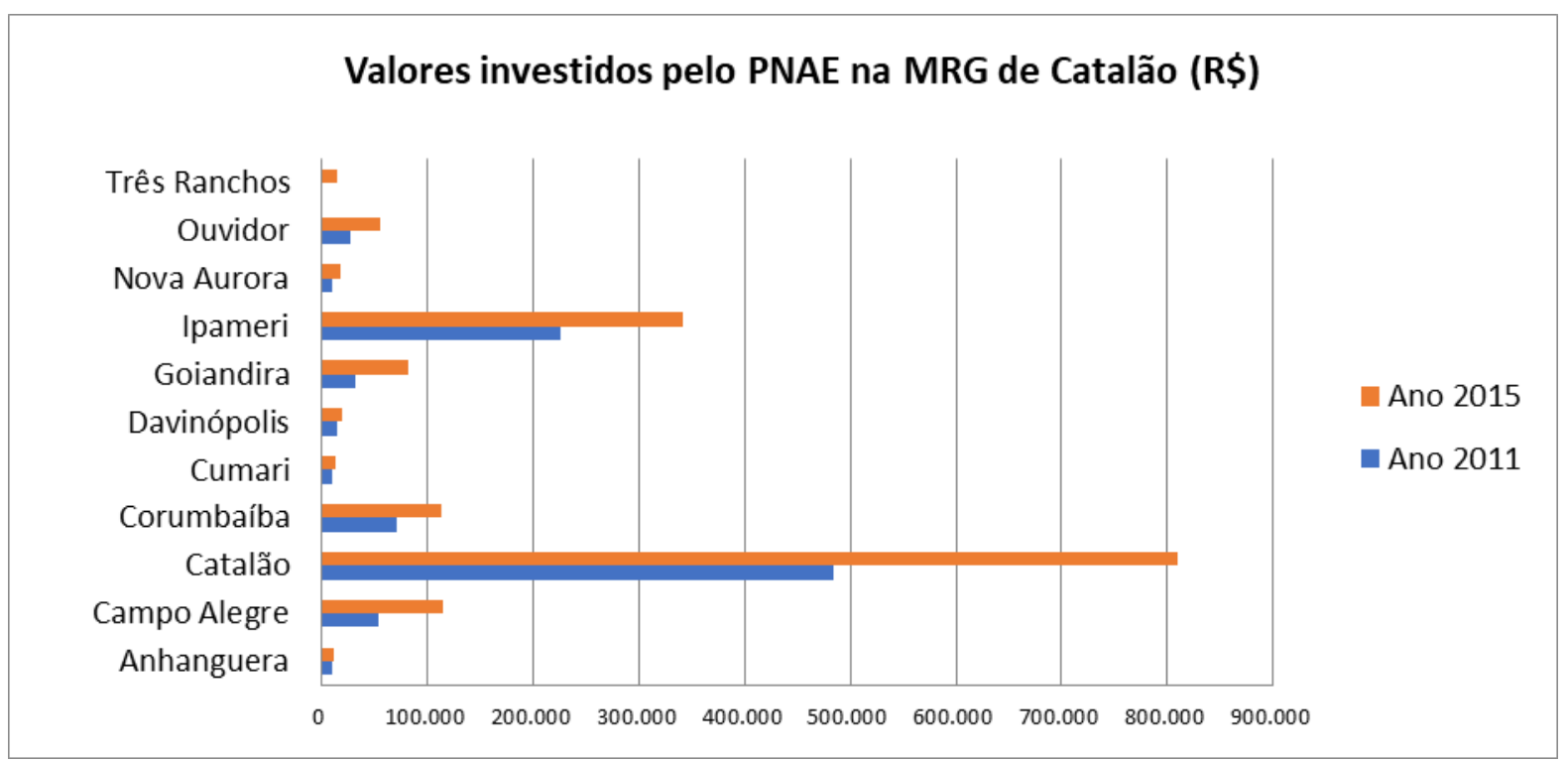

Gráfico 1: Investimento do PNAE nos municípios da MRG de Catalão

O gráfico 1 remete à quantidade de recursos destinados aos municípios da MRG de Catalão nos anos de 2011 (azul) e 2015 (vermelho). Ao todo, foram aplicados pelo programa $\mathrm{R}$ \$ R 939.660,00 e R\$ 1.590.920,00, respectivamente por ano, demonstrando que em todos os casos, houve um maior investimento em 2015 (não haviam dados para o município de Três Ranchos em 2011). Nota-se uma grande discrepância entre a quantidade destinada a alguns municípios em relação a outros. Catalão foi o município que mais recebeu recursos. Na avaliação mais recente, mais de $\mathrm{R} \$ 800.000,00$ foram investidos pelo PNAE, ao passo que Ipameri, segundo município que mais recebeu esses recursos, não obteve nem metade do recurso destinado à Catalão.

Os dois municípios citados possuem como características semelhantes o fato de que são os que possuem o maior número de habitantes, além dos maiores PIBs da microrregião. Em contrapartida, municípios como Anhanguera, Cumari, Davinópolis, Nova Aurora e Três Ranchos mostram pouca expressividade na quantidade de habitantes (nenhum ultrapassando 
os 4.000 habitantes) e também no recebimento de recurso do PNAE, tanto em 2011, quanto em 2015.

A seguir, no gráfico 2 referente ao mesmo aspecto e recorte temporal em análise, são apresentados os dados para a Microrregião do Sudoeste de Goiás. Rio Verde e Jataí foram os municípios de destaque nos recursos, recebendo em 2015 valores superiores a faixa do milhão (o primeiro atingindo mais de $\mathrm{R} \$ 2.000 .000,00$ e o segundo $\mathrm{R} \$ 1.000 .000,00$ ). Mineiros também se tornou um dos municípios que mais receberam do PNAE, atingindo quase $\mathrm{R} \$$ 700.000,00 no último ano.

Esses três municípios que se destacaram são os que possuem mais habitantes da região, dispondo dos maiores índices de PIB e se apoiam sob uma das bases mais sólidas de agropecuária no estado.

Ao todo, foram destinados à Microrregião no ano de $2011 \mathrm{R} \$ 3.551 .076,00$, valor esse que subiu para $\mathrm{R} \$$ 5.325.910,00 em 2011. Nos mesmos períodos, a Microrregião de Catalão respectivamente $\mathrm{R} \$$ 939.660,00 e $\mathrm{R} \$$ 1.590.920,00, indicando um aumento pouco mais tímido de repasse federal.

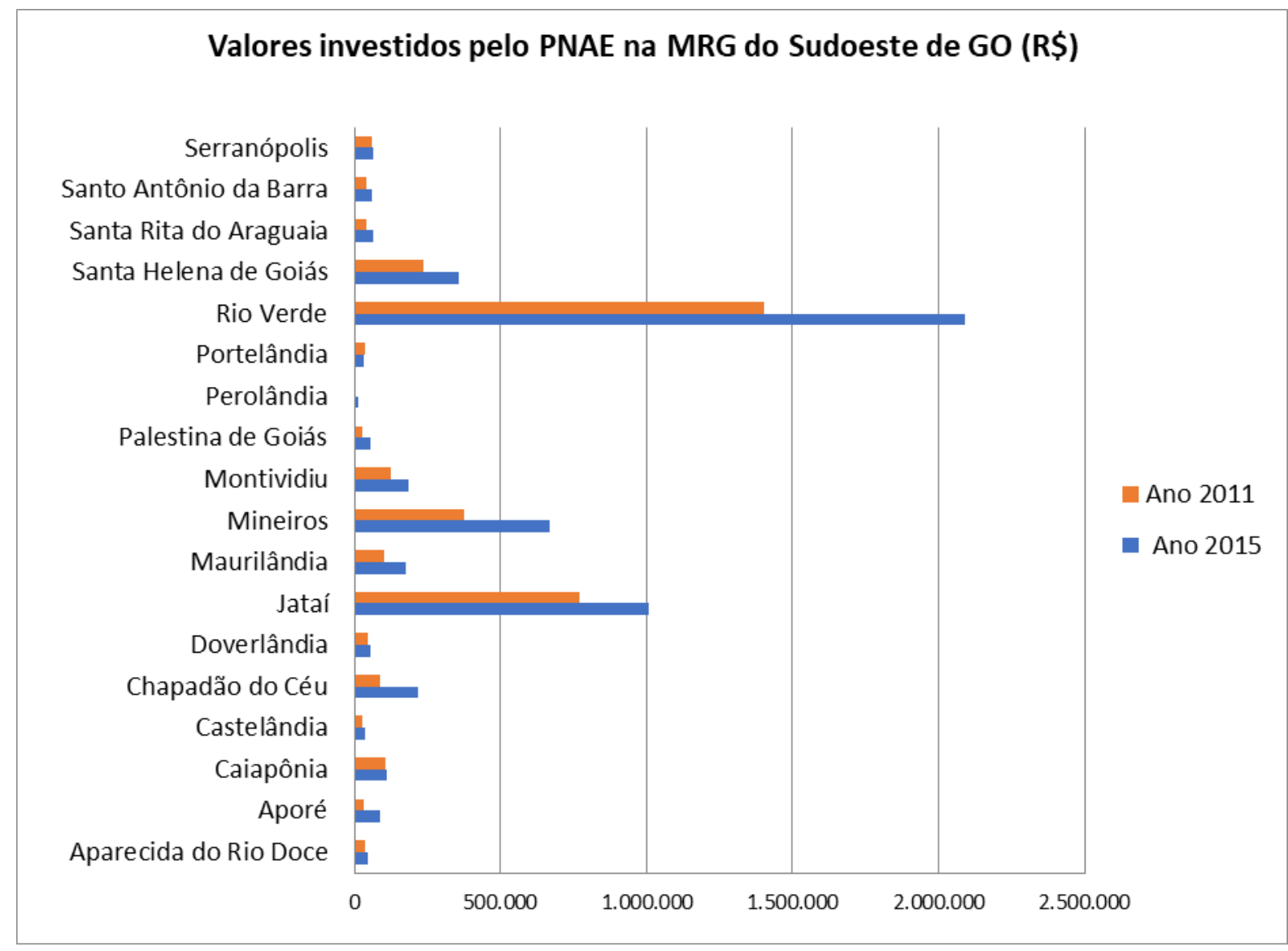

Gráfico 2: Investimento do PNAE nos municípios da MRG de Catalão 


\section{O PROGRAMA NACIONAL DE PRODUÇÃO E USO DE BIODIESEL (PNPB)}

Datado de 06 de dezembro de 2004, quando fora publicada a Lei 11.097 que concebe o biodiesel no âmbito da matriz energética do país, o Programa Nacional de Produção e Uso do Biodiesel (PNPB) é caracterizado por ser um programa interministerial que se baseia na implementação de um programa sustentável, que promova a inclusão social por meio da geração de renda e emprego, garantindo preços competitivos, produzindo o combustível a partir de diferentes fontes oleaginosas, fortalecendo as potencialidades de cada região brasileira para a produção da matéria prima (BRASIL, sem data).

Com a evolução do PNPB, em nível nacional, as principais matérias primas oleaginosas para a produção do combustível passaram a ser: soja, gordura bovina, algodão, materiais graxos, gordura de frango, gordura de porco, óleo de fritura usado, girassol e palma, respectivamente nesta ordem de quantidade produzida, segundo análise realizada por Peixoto (2016).

A Lei 11.097 determinou a obrigatoriedade da adição de um percentual mínimo de biodiesel ao diesel usual (SILVA, 2010) "com o objetivo de substituir total ou parcialmente o diesel fóssil utilizado no país" (RESENDE, 2015, p. 15). Deste modo, houve alterações no percentual original, sendo que a:

[...] proposta inicial foi a introdução de $2 \%$ (dois por cento) do biodiesel no diesel comum até 2008 e de 5\% (cinco por cento) até 2013 (BRASIL, 2005; ABRAMOVAY e MAGALHÃES, 2007). Em função da capacidade instalada e benefícios para a cadeia do biodiesel, já em 2010 o marco de $5 \%$ (cinco por cento) foi estabelecido (CNPE, 2009), aumentando para 6\% (seis por cento) em julho de 2014 e para $7 \%$ (sete por cento), a partir de $1^{\circ}$ de novembro de 2014 (BRASIL, 2014). - (RESENDE, 2015, p. 15).

O programa possui como instrumento de inclusão social o "Selo Combustível Social". A cartilha do PNPB garante que os produtores de biodiesel recebam o selo do extinto Ministério do Desenvolvimento Agrário (MDA) por promover o desenvolvimento regional e gerar renda às famílias de agricultores que produzem a matéria prima, promovendo assim a inclusão. Com o selo, o produtor recebe benefícios, tais como: diferenciação/isenção nos tributos PIS/PASEP e COFINS; acesso às melhores condições de financiamento junto aos bancos; possibilidade de uso do Selo Combustível Social para promover sua imagem no mercado" (BRASIL, sem data). 


\section{RESULTADOS DO PNPB PARA O ESTADO DE GOIÁS}

O Programa Nacional de Produção e Uso de Biodiesel (PNPB) se difere do PAA sobretudo quanto aos produtos gerados e o mercado comprador. Enquanto o segundo visa a produção de alimentos para o Estado, o primeiro produz oleaginosas comercializa os produtos em maioria para entidades privadas, podendo ter mediações de cooperativas e associações (RIBEIRO; DIAS, 2013).

Silva (2016) elaborou a tabela 1, a seguir, referente à evolução do programa em Goiás dentre os anos de 2008 (ano de início de seu início no estado) e 2015, gerando-se as seguintes informações:

Tabela 1: Dados do Selo Combustível Social - PNPB em Goiás - 2008 a 2015

\begin{tabular}{c|c|c|c|c}
\hline Ano & $\mathbf{N}^{\mathbf{0}}$ de Famílias & $\begin{array}{c}\mathbf{N}^{\mathbf{0}} \text { de } \\
\text { Cooperativas }\end{array}$ & $\begin{array}{c}\text { Volume de } \\
\text { matéria prima } \\
\text { ( mil } \\
\text { toneladas) }\end{array}$ & $\begin{array}{c}\text { Valor } \\
\text { (milhões R\$) }\end{array}$ \\
\hline $\mathbf{2 0 0 8}$ & 945 & 1 & 71,26 & 73,94 \\
\hline $\mathbf{2 0 0 9}$ & 1.094 & 2 & 175,19 & 133,11 \\
\hline $\mathbf{2 0 1 0}$ & 1.672 & 2 & 247,96 & 148,45 \\
\hline $\mathbf{2 0 1 1}$ & 1.819 & 4 & 243,81 & 181,49 \\
\hline $\mathbf{2 0 1 2}$ & 2.066 & 9 & 309,44 & 251,92 \\
\hline $\mathbf{2 0 1 3}$ & 2.249 & 10 & 315,73 & 290,83 \\
\hline $\mathbf{2 0 1 4}$ & 1.970 & 9 & 293,71 & 299,96 \\
\hline $\mathbf{2 0 1 5}$ & 1.887 & 7 & 297,87 & 300,35 \\
\hline
\end{tabular}

Fonte: SIC-SAF/MDA. Adaptado e organizado: SILVA, K.P., 2016.

O crescimento positivo em todos os quesitos abordados demonstra uma maior integração do programa na rede de produção goiana. Apesar do aumento entre do número de famílias, cooperativas, volume e valores atingidos, houve uma grande redução na diversidade das matérias primas produzidas. Ribeiro e Dias (2013) afirmam que a soja dominava $80 \%$ do mercado nacional de oleaginosas destinadas à produção de biocombustíveis em 2010. Para o Centro-Oeste, Silva (2016) utiliza dados da ANP - Agência Nacional do Petróleo, Gás Natural e Biocombustíveis - e conclui que em 2015, a matriz produtora da região era composta por mais de $91 \%$ de soja.

Segundo Ribeiro e Dias (2013), ambos os programas, mas, sobretudo o PNPB, acabam por interferir em seus territórios e padrão de vida, impondo um cotidiano burocrático que não faz parte do modo de vida camponês. 


\section{CONSIDERAÇÕES FINAIS}

Os dados e informações apontam um maior investimento na Microrregião do Sudoeste de Goiás. Apesar de não terem sido encontrados dados pormenorizados do Programa Nacional de Produção e Uso de Biodiesel para as MRGs e os municípios que as compõem, os resultados encontrados com o PAA e PNAE indicam este fato. A região, se constitui na maior referência em agropecuária do estado além de ser uma das mais ricas, recebendo grandes repasses federais. A Microrregião de Catalão também apresenta resultados expressivos, tanto no que se refere a investimento, quanto à produção.

As informações pertinentes a alguns dos anos de execução dos programas analisados refletem um panorama de envolvimento social de agentes priorizados. Estes programas vieram para agregar os agricultores familiares, assentados rurais e comunidades tradicionais na matriz comercial, e seus desempenhos, ainda que com limitações, trouxeram benefícios a essas populações.

Apesar de os dados não apresentarem um crescente absoluto desde o princípio, as quedas de número de agricultores, valores e produtos gerados não diminuem a relevância da inclusão de políticas públicas no espaço rural.

Contudo, é importante ressaltar que a execução desses programas, especialmente o PNPB, se dá de forma bastante divergente do que se espera. A falta de diversidade produtiva - notadamente ancorada na soja -, as condições impróprias de trabalho, a forma de comercialização da matéria-prima, dentre outras, demonstra a prática de uma das formas mais vorazes do capitalismo. A perda da autonomia rural em detrimento do ajuste no modo de vida que os camponeses devem efetuar para se adequar a forma de manuseio e produção da terra imposta, contrapondo o bem-viver dos camponeses à lógica mercadológica retroalimentada pelos mecanismos de estruturação e controle das políticas públicas.

Tal conjuntura nos coloca diante de algumas reflexões basilares acerca do desenvolvimento rural, indubitavelmente circunscritas à questão agrária brasileira, e por conseguinte, a reforma agrária. A nosso ver, toda e qualquer ação política que esteja desarticulada à esta questão, está sujeita a uma série de problemas, e, em última instância, ao fracasso. 
Em Goiás, a estrutura fundiária concentrada, reproduz o cenário nacional, considerando que conforme os dados do Censo Agropecuário do IBGE de 2006 , o número de estabelecimentos agropecuários, conduzidos pela "agricultura familiar" representava 65,0\% do total (perfazendo 88.436) ocupando uma área total de apenas 13,0\% do estado (3.329.630 hectares). Em contrapartida, os estabelecimentos de agricultura "não-familiar", ou seja, conduzidos pela agricultura capitalista, equivaliam a 35,0\% do total de estabelecimentos, mas ocupavam o equivalente a $87,0 \%$ do total da área agricultável naquele período no estado.

Se correlacionarmos a abrangência dos Programas analisados neste artigo, com o contingente de camponeses que perfazem os números da "agricultura familiar" apresentado pelo Censo Agropecuário (2006), constatamos o seguinte cenário:

- Em $2015^{5}$ o Programa de Aquisição de Alimentos (PAA) abrangeu 2.114 agricultores em Goiás, o que equivale a $2,4 \%$ da agricultura familiar sistematizada pelo Censo Agropecuário de 2006. No plano nacional, o PAA abrangeu 95.871 agricultores, o que perfaz 2,2\% do contingente integrado pela agricultura familiar.

- Em $2015^{6}$ o Programa Nacional de Produção e Uso do Biodiesel (PNPB) abrangeu 1.887 agricultores em Goiás, com base nos dados do Selo Combustível Social, o que equivale a $2,1 \%$ da agricultura familiar sistematizada pelo Censo Agropecuário de 2006. Em escala nacional, o PNPB abrangeu 72.485 agricultores, o que perfaz a 1,6\% do contingente integrado pela agricultura familiar.

- Quanto ao Programa Nacional de Alimentação Escolar (PNAE), os dados disponíveis estão circunscritos aos repasses para o nível municipal e disponibilizados pelo Fundo Nacional de Desenvolvimento Escolar (FNDE). Considerando que em 2015 foram repassados $\mathrm{R} \$ 25.608,734$, para o estado de

\footnotetext{
${ }^{4}$ É importante registrar que o Censo Agropecuário de 2006, realizou e sistematizou os dados com base na Lei da Agricultura familiar - Lei $\mathrm{n}^{\circ}$ 11.326. Conforme os dados apresentados, o contingente composto pela Agricultura Familiar no Brasil perfaz o número de 4.367 .902 estabelecimentos agropecuários $(84,4 \%$ do total), ocupando uma área de 80.250 .453 ha (24,3\% do total). Por sua vez, a agricultura "não-familiar" perfaz o número de 807.587 estabelecimentos agropecuários (15,6\% do total), ocupando uma área de 249.690 .940 ha $(75,7 \%$ do total). Para Goiás a agricultura familiar perfaz 88.436 estabelecimentos (65,0\% do total), ocupando uma área de 3.329 .630 ha (13,0\% do total). Já a agricultura "não-familiar" em Goiás, perfaz 47.247 estabelecimentos (35,0\% do total), ocupando uma área de 22.353 .918 ha (87,0\% do total).

${ }_{6}^{5}$ Última sistematização apresentada pela Secretaria de Avaliação e Gestão da Informação (SAGI).

${ }^{6}$ Conforme os dados do Sistema de Informação por Município da Secretaria Especial de Agricultura Familiar e do Desenvolvimento Agrário (SEAD) em 2018. Para efeito de comparação com os demais Programas, utilizouse a base de 2015, mas os dados para o PNPB estão disponíveis até o ano de 2016 e perfazem 1.730 agricultores ( $1,9 \%$ da agricultura familiar do estado) para Goiás e 70.255 agricultores (1,6\% da agricultura familiar nacional) para o Brasil.
} 
Goiás, se dividirmos esse montante com o contingente da agricultura familiar no estado, chegaríamos a inacreditáveis $\mathrm{R} \$ 289,57$ por agricultor neste mesmo ano. Em nível nacional esse montante cairia para a média de $\mathrm{R} \$ 196,56$ por agricultor familiar naquele ano de 2015.

Diante deste quadro, observamos que em que pese a relevância das políticas públicas que têm eleito a "agricultura familiar" como foco de ação, a sua abrangência ainda é muito reduzida, tanto pela dotação orçamentária que é incompatível com o contingente composto pela agricultura camponesa. Afinal, os dados do Censo Agropecuário do IBGE (2006) apresentam um total de 4.367.902 estabelecimentos agropecuários que possuem a "agricultura familiar" como condutora do processo produtivo, mas que se encontra "encurralada" em 24,3\% da área agricultável disponível no território brasileiro. Isso sem falar da heterogeneidade social das frações de classe que compõem a agricultura camponesa brasileira.

Outrossim, salientamos a necessidade de concatenar as políticas públicas de desenvolvimento rural com a distribuição fundiária, que deve ser ancorada a uma reforma agrária efetivamente estrutural.

Além do alcance das políticas públicas ser reduzido do ponto de vista da correlação entre agricultores contemplados e o montante de recursos alocados para este fim, ainda temos a tendência de concentração nas regiões que demonstram maior capacidade de especialização produtiva, notadamente naquelas dotadas de melhores condições infraestruturais, conforme evidenciado em Goiás, em que os programas analisados tiveram os resultados mais efetivos nas microrregiões de Catalão e do Sudoeste do estado, que se destacam como produtoras de commodities para exportação.

A formação de um banco de dados capaz de sistematizar os dados e informações acerca deste tema é importante para a compreensão do tema desenvolvimento rural. Entretanto, a análise não pode se basear tão somente nos números e dados estatísticos, mas também em informações qualitativas - permeadas em referenciais teóricos - que permitam se aproximar da totalidade complexa que compõe o espaço agrário brasileiro. 


\section{REFERÊNCIAS}

BRASIL. Companhia Nacional de Abastecimento (CONAB). Quem somos. Disponível em: <http://www.conab.gov.br/conab-quemSomos.php?a=11\&t=1>. Acesso em: 15 jul. 2017.

BRASIL. Fundo Nacional de Desenvolvimento da Educação. Sobre o PNAE. 2012. Disponível em: <http://www.fnde.gov.br/programas/alimentacao-escolar/alimentacao-escolarapresentacao>. Acesso em: 14 jul. 2017.

BRASIL. Fundo Nacional de Desenvolvimento da Educação (FNDE). Aquisição de produtos da agricultura familiar para o programa nacional de alimentação Escolar. 2012. Disponível em: <http://www.fnde.gov.br/programas/alimentacao-escolar/agricultura-familiar>. Acesso em: 14 jul. 2017.

BRASIL. Ministério de Desenvolvimento Agropecuário (MDA) / Secretaria Especial de Agricultura Familiar e Desenvolvimento Agrário. Programa Nacional de Produção e Uso de Biodiesel: inclusão social e desenvolvimento territorial. Disponível em: <http://www.mda.gov.br/sitemda/sites/sitemda/files/user_arquivos_64/Biodiesel_Book_final_ Low_Completo.pdf>.Acesso em: 14 jul. 2017.

BRASIL. Ministério do Desenvolvimento Sustentável (MDS). Programa de Aquisição de Alimentos - PAA. 2015. Disponível em: <http://mds.gov.br/assuntos/segurancaalimentar/programa-de-aquisicao-de-alimentos-paa/programa-de-aquisicao-de-alimentos> . Acesso em 14 jul. 2017.

BRASIL. Ministério da Educação; Fundo Nacional de Desenvolvimento da Educação (FNDE). Cartilha Nacional da Alimentação Escolar. 2014. Disponível em: <http://www.educacao.sp.gov.br/a2sitebox/arquivos/documentos/960.pdf $>$. Acesso: 14 jul. 2017.

BRASIL. Secretaria Especial de Agricultura Familiar e do Desenvolvimento Agrário. PAA Disponível em: <http://www.mda.gov.br/sitemda/secretaria/saf-paa/sobre-o-programa> Acesso em: 14 jul. 2017.

BRASIL. Secretaria Especial de Agricultura Familiar e do Desenvolvimento Agrário. SAF. Disponível em: <http://www.mda.gov.br/sitemda/secretaria/saf-creditorural/sobre-oprograma>. Acesso em: 14 jul. 2017.

COSTA, Bianca Aparecida Lima; AMORIN JÚNIOR, Paulo Cesar Gomes; SILVA, Marcio Gomes da. As Cooperativas de agricultura familiar e o mercado de compras governamentais 
em Minas Gerais. Revista de Economia e Sociologia Rural. Vol.53 Nº.1. Brasília Jan./Mar. 2015.

ESTADO DE GOIÁS, Secretaria de Estado de Gestão e Planejamento (SEGPLAN), Instituto Mauro Borges de Estatísticas e Estudos Socioeconômicos (IMB). Mapas das Microrregiões de Goiás - IBGE. http://www.imb.go.gov.br/viewmapa.asp?mapa=Mapas\%20das\%20Microrregi\%F5es\%20de \%20Goi\%E1s\%20-\%20IBGE>. Acesso em: 21 jul. 2017.

OLIVEIRA, Bruno Carneiro de. Análise sobre a região metropolitana de Goiânia e microrregião sudoeste de Goiás pela ótica de receitas públicas tributárias nos anos de 2010 e 2015. 2017. 132 f. Dissertação (Mestrado em Geografia) - Universidade Federal de Goiás, Goiânia, 2017.

PEIXOTO, Ângela Maria Martins. Políticas públicas e agricultura camponesa: análise do PAA e do PNPB nos municípios de Ipameri e Jataí-GO. 2016. 236 f. Dissertação (Mestrado em Geografia) - Instituto de Estudos Socioambientais, Programa de Pós-Graduação em Geografia, Universidade Federal de Goiás. Goiânia, 2016.

RESENDE, Renata Maria De Miranda Rios. O Programa Nacional Para Produção e Uso do Biodiesel na realidade da Agricultura Familiar de Rio Verde-GO. 2015. 101 f. Dissertação (Mestrado em Agronegócio) - Escola de Agronomia, Programa de Mestrado em Agronegócio - PPAGRO, da Universidade Federal de Goiás. Goiânia, 2015.

RIBEIRO, Dinalva Donizete; DIAS, Mariza Souza. Políticas Públicas para a agricultura familiar: O PAA е о PNPB. Mercator, Fortaleza, v. 12, n. 27, p. 81-91, jan./abr. 2013.

SANTOS, Júnio Gregório Roza dos. Avaliação geoambiental comparada de assentamentos rurais das Regiões Nordeste e Sul do estado de Goiás. 2016. Disponível em: <http://www.labogef.iesa.ufg.br/labogef/arquivos/downloads/JUNIO_GREGORIO_MONOG RAFIA_CORRIGIDA_FINAL_44831.pdf>. Acesso em: 15 jul. 2017.

SECCHI, Leonardo. Políticas públicas: conceitos, esquemas de análises, casos práticos. 2. Edição. São Paulo: Cengage Learning, 2013. 168 p.

SILVA, Karinne de Pina. Políticas públicas e desenvolvimento rural em Goiás: Análise a partir do PAA e PNPB. 2016. 25f. Universidade Federal de Goiás, Goiânia. 